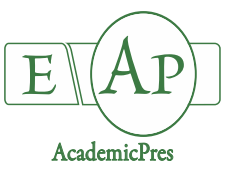

Hu D etal. (2021)

Notulae Botanicae Horti Agrobotanici Cluj-Napoca

Volume 49, Issue 2, Article number 12200

DOI: $10.15835 /$ nbha 49212200

Research Article

\title{
Effects of ABT on the morphogenesis and inclusions of Taxus chinensis (Pilger) Rehd f. baokangsis cutting rooting
}

\author{
Die HU, Xinru HE, Yongzheng MA, Yongjun FEI* \\ Yangtze University, College of Horticulture and Gardening, Jingzhou Hubei 434025, China; hudie.16@163.com; \\ 1293446583@qq.com;825437637@qq.com; fyj2010@163.com (*correspondingauthor)
}

\begin{abstract}
This study aims to explore the cutting propagation method of a novel variant on Taxus chinensis (Pilger) Rehd f. baokangsis ( T. chinensis baokangsis). Different types of rooting powder and different concentrations were used to treat the cuttage seedlings of $T$. chinensis baokangsis, and then the external morphology and anatomical morphology of the roots were observed. The membership function evaluation method was used to evaluate the cutting effect. The physiological characteristics of $T$. chinensis baokangsis cuttings were studied by the correlation analysis of nutrient components and endogenous hormone content. The results showed that the $T$. chinensis baokangsis belonged to callus rooting type, and the adventitious roots differentiated at about $150 \mathrm{~d}$. For rooting growth indexes, the optimal treatment was ABT-1+400 mg/L. The rooting rate of $T$. chinensis baokangsis was positively correlated with the content of soluble sugar, soluble starch, and IAA, while extremely significantly negatively correlated with MDA $(P<0.01)$. Moreover, the rooting rate also was negatively correlated with $\mathrm{ABA}, \mathrm{ZR}$, and GA3, and significantly negatively correlated with $\mathrm{GA}_{3}(P<0.05)$. This study will provide some technical support and theoretical basis for the conservation and reproduction of $T$. chinensis baokangsis.
\end{abstract}

Keywords: ABT; cuttings; Taxus chinensis (Pilger) Rehd f. baokangsis

\section{Introduction}

Taxus chinensis ( $\mathrm{Pilger}$ ) Rehd f. baokangsis (T. chinensis baokangsis) is a new variant of Taxus chinensis var. mairei, which is monoecious in that fruit develops on male branches or male cone develop on female branches (Fei et al., 2019). Due to the low natural reproduction capacity of Taxus plants, the existing resources of T. chinensis baokangsis are scarce and rapid propagation is required (Li et al., 2011; Fei and Tang, 2018).

The application of the plant growth regulator is a special method to promote the rooting of difficultrooted plants. Growth regulators can accelerate the growth and division of cuttage cells, and promote the flow of nutrients that can be directly available by plants to the base of cutting, and activate the cambium, and finally facilitate the generation of root primordia (Babaie et al., 2014; Zhang et al., 2017). The actual effect of growth regulators is not only related to the biological characteristics of plants but also closely related to the types of growth regulators and the concentration and time of process of cutting (Li et al., 2007; Kose et al., 2011).

Received: 24 Dec 2020. Received in revised form: 10 Apr 2021. Accepted: 27 Apr 2021. Published online: 06 May 2021.

From Volume 49, Issue 1, 2021, Notulae Botanicae Horti Agrobotanici Cluj-Napoca journal uses article numbers in place of the traditional method of continuous pagination through the volume. The journal will continue to appear quarterly, as before, with four annual numbers. 
$\mathrm{ABT}$ rooting powder is a kind of growth regulator with excellent results in practical application and that has been popularized in cuttage seedlings technology. Tan (2014) found that treating Tamarix chinensis shoot cuttings with $\mathrm{ABT}$ at $200 \mathrm{mg} \mathrm{L}^{-1}$ for one hour increased biomass and rooting percentage to $84.4 \%$ on average.

T. chinensis baokangsis is a new germplasm resource with less natural stock. Therefore, to improve the conservation and reproduction efficiency of $T$. chinensis baokangsis germplasm resources and explore the cutting propagation technology of $T$. chinensis baokangsis, in this study, three kinds of ABT root powder and three kinds of concentration of plant growth regulator were used for cutting treatment. Then, physiological and endogenous hormone indexes in each group were measured, and correlation analysis was conducted to study the physiological characteristics of $T$. chinensis baokangsis cutting. Our study provided certain technical support and a theoretical basis for future development and utilization of T. chinensis baokangsis.

\section{Materials and Methods}

\section{Experimental materials}

Healthy, disease-free and one-year-old semi-lignified branches were selected from the mother trees of $T$. chinensis baokangsis in the nursery of Runjing Garden Company, Jianli, Jingzhou, China. The branches were immediately moistened after collection and brought back to the laboratory of Yangtze University. The branch with the same specifications were selected and cut into $15-20 \mathrm{~cm}$ cuttings, with the upper port flat and the lower port inclined plane. All cuttings were reserved about 30 leaves on the upper part, and then disinfected with $80 \%$ carbendazole with diluted 1000 times. Finally, cuttings were inserted into a red plastic basin (upper diameter $17 \mathrm{~cm} \times$ lower diameter $12 \mathrm{~cm} \times$ height $15 \mathrm{~cm}$ ), and which was filled with a matrix of uniformly mixed vermiculite: perlite $(3: 1)$.

\section{Experimental design}

Two influencing factors were set for cutting experiments, which was different kinds of root powder and growth regulator with different concentration gradient. Three concentration gradients of ABT were set as B1 (400 mg/L), B2 (200 mg/L) and B3 (100 mg/L), as shown in Table 1.

Table 1. Different treatment methods in the experiment design

\begin{tabular}{|l|c|c|c|c|}
\hline Treatment & B1 $(400 \mathrm{mg} / \mathrm{L})$ & $\mathrm{B} 2(200 \mathrm{mg} / \mathrm{L})$ & $\mathrm{B} 3(100 \mathrm{mg} / \mathrm{L})$ & Water \\
\hline A1 $(\mathrm{ABT}-1)$ & $\mathrm{A} 1 \mathrm{~B} 1$ & $\mathrm{~A} 1 \mathrm{~B} 2$ & $\mathrm{~A} 1 \mathrm{~B} 3$ & \multirow{2}{*}{$\mathrm{CK}$} \\
\cline { 1 - 3 } $\mathrm{A} 2(\mathrm{ABT}-2)$ & $\mathrm{A} 2 \mathrm{~B} 1$ & $\mathrm{~A} 2 \mathrm{~B} 2$ & $\mathrm{~A} 2 \mathrm{~B} 3$ & \\
\hline $\mathrm{A} 3(\mathrm{ABT}-3)$ & $\mathrm{A} 3 \mathrm{~B} 1$ & $\mathrm{~A} 3 \mathrm{~B} 2$ & $\mathrm{~A} 3 \mathrm{~B} 3$ & \\
\hline
\end{tabular}

Observation of the rooting process

The adventitious roots of the cutting group and control group were collected, washed, and placed in glass bottles containing 70\% FAA and fixed for $48 \mathrm{~h}$. The bottles were sealed with a lid during the period, and then made into paraffin sections for observation.

\section{Rooting statistics}

After the cutting cuttage was started, the growth status of the roots of the cuttings was observed irregularly. The callus and adventitious roots were regularly recorded after $30 \mathrm{~d}$. The rooting locations were recorded at $210 \mathrm{~d}$ and the rooting situation of all cuttage was counted. Recorded rooting indicators included rooting rate (\%), callus rate (\%), freshness rate (\%), and rooting index. The rooting index is an indicator for a comprehensive evaluation of the rooting effect, which represents the average total root length of a single cuttage seedling. The calculation formula of rooting index as following: number of adventitious roots $\times$ adventitious root length $\times$ rooting rate. 


\section{Determination of soluble substances}

To prepare enzyme extraction, about $0.2 \mathrm{~g}$ of leaf samples were homogenized with $1.6 \mathrm{~mL}$ of $150 \mathrm{mM}$ buffer solution (containing 0.7 of $\mathrm{NaH}_{2} \mathrm{PO}_{4} \cdot 2 \mathrm{H}_{2} \mathrm{O}$ and $1.64 \% \mathrm{Na}_{2} \mathrm{HPO}_{4} \cdot 12 \mathrm{H}_{2} \mathrm{O}, \mathrm{pH} 7.8$ ) subjected to grinding with an ice-cooled mortar and pestle and finally centrifuged at $12000 \mathrm{rpm}$ for $20 \mathrm{~min}$ at $4{ }^{\circ} \mathrm{C}$. The supernatant was collected for the determination of the content of soluble protein, soluble sugar and MDA. The soluble protein and soluble sugar content were estimated as described by Moustakas (2011). The MDA content was established by the method of $\mathrm{Li}(2010)$.

\section{Determination of endogenous hormone content}

Samples of adventitious roots from each group were collected and washed, and then sent to China Agricultural University after treated with fresh-keeping to determine the content of endogenous hormones using enzyme-linked immunosorbent assay.

\section{Statistical analysis}

Data are presented as mean value of each treatment. The results represent the means \pm standard error with each experiment performed in triplicate. Data were analyzed with one-way ANOVA using SPSS 10.0 for Windows (SPSS Inc., IL, USA), and differences in the treatment means were compared with Duncan's multiple range test at the $P<0.05$ level.

\section{Results}

Observation of the external morphology during the process of cutting rooting of T. chinensis baokangsis

The annular intumescence was observed at the incisions at the base of some cuttages at $60 \mathrm{~d}$ after cutting (Figure 1-A). The entire annular was composed of a large number of small projections, and the overall appearance was dark brown. At $90 \mathrm{~d}$ after cutting, the annular swelling at the incision at the base of the cuttings became larger and larger, and observed small white semi-transparent protuberance on the annular intumescence (Figure 1-B). Thereafter, the white semi-transparent protuberance became larger and larger and gradually covered the whole cutting surface. 150 days after cutting, adventitious roots broke through the callus and grew, but the number was small, about 2-3 (as shown in Figure 1-C, Figure 1-D). The adventitious roots were observed in the callus of most cuttings at $165 \mathrm{~d}$ (Figure 1-E). After cutting for $180 \mathrm{~d}$, adventitious roots gradually grew to about $3 \mathrm{~cm}$ in length (Figure 1-F). At $195 \mathrm{~d}$ after cutting, the first-level lateral root has grown out from adventitious roots which had thickened (Figure 1-G and Figure 1-H). The rooting indexes of callus were counted at $210 \mathrm{~d}$ after cutting, and the results showed that most of the callus protruded adventitious roots. In addition, a large number of roots have grown at the base of the cuttings, and both of the adventitious roots and the lateral roots on the adventitious roots were longer and more numerous (Figure 1-I and Figure 1-J). Therefore, these results indicated that after cutting for 210 days, a complete root system that can be transplanted has been formed (Figure 1-K). 

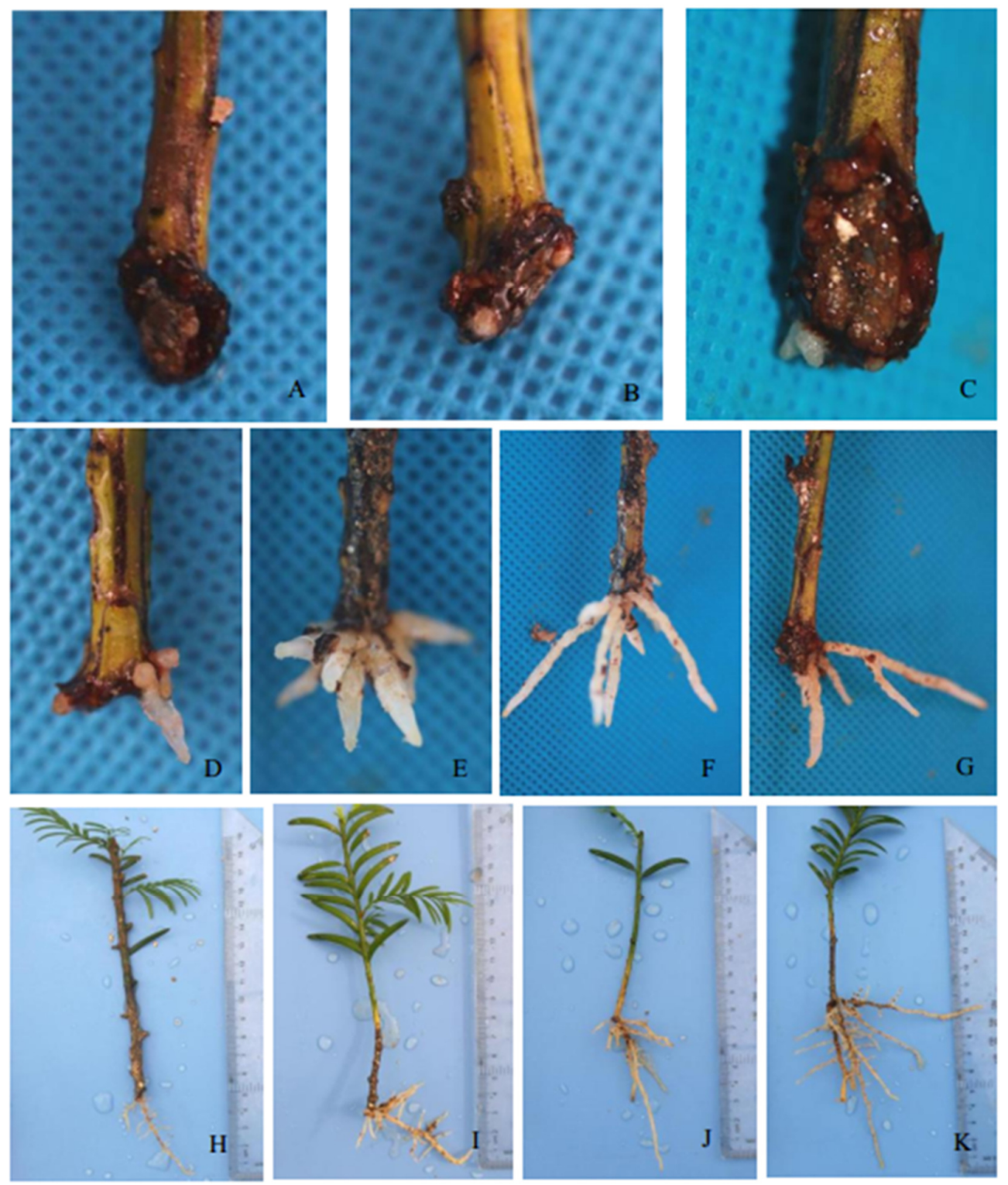

Figure 1. Morphologic character observation on the cutting rooting of Taxus chinensis (Pilger) Rehd $\mathrm{f}$. baokangsis Y. J. Fei

(Figure 1-A: After 60 days of cutting, dark brown ring swelling appeared at the base of some cuttings; Figure 1-B: 90 days after cutting, the ring swelling became larger and larger, and white translucent small bulge appeared on the ring swelling; Figure 1-C, 1-D: After 150 days of cutting, adventitious roots grew from callus, and the number of adventitious roots was small, about 2-3: Figure 1-E: 165 days after cutting, the adventitious roots of most cuttings grew out of callus, and the number of adventitious roots was large; Figure 1-F: After 180 days of cutting, the adventitious roots increased gradually, about $3 \mathrm{~cm}$ in length; Figure 1-G, 1-H: After 195 days, adventitious roots grew on the adventitious roots, and the adventitious roots became thicker; Figure 1-I, 1-J: At 210 days after cutting, most of the adventitious roots extended from the callus, and a large number of roots had grown at the base of cuttings, both adventitious roots and lateral roots on adventitious roots were longer and more; Figure 1-K: The whole root system can be transplanted.) 
The anatomical structure of the transection section and longitudinal section of tender roots of the cutting propagation of $T$. chinensis baokangsis were shown in Figure 2. The tender roots of cuttings were composed of epidermis, cortex, and vascular column. As shown in Figure 2, the epidermal cells were arranged neatly and tightly. The cortex was composed of the outer cortex, the endodermis (smaller and more densely arranged cells), and the cortical parenchyma cells (larger cells and more layers) (Figure 2). The vascular sheath, primary xylem, and primary phloem belong to the vascular column, while the primary xylem includes the guide cell and the parenchyma cell, showing the radiation Angle of the two prototype states. The vascular bundle sheath, primary xylem, and primary phloem belong to the vascular column, while the primary xylem includes the tracheids and the xylem parenchyma cell, and exist as the radiation angle of the diarch.
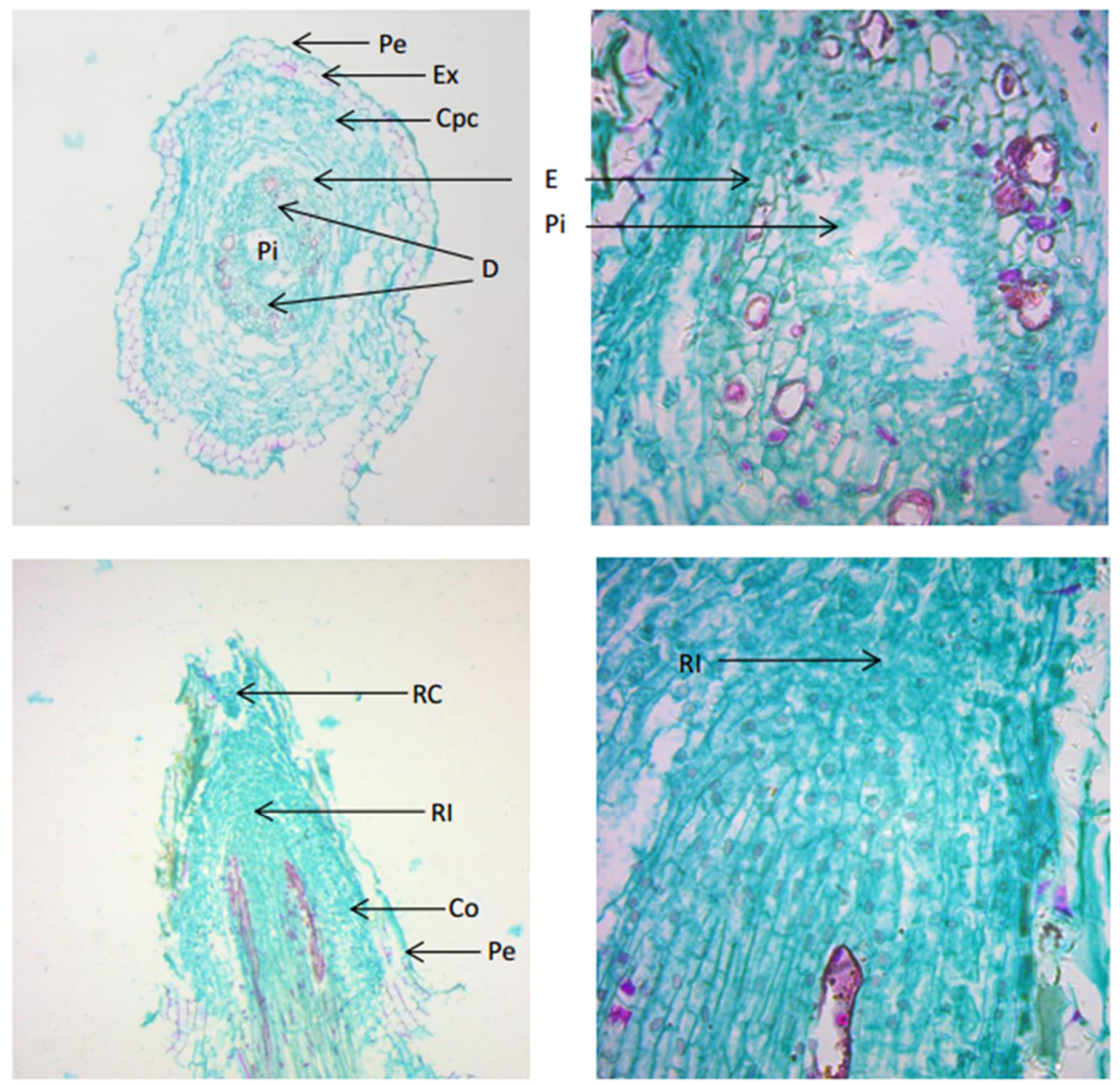

Figure 2. Anatomical structure of the transverse and longitudinal sections of the tender root

(Pe: Periderm; Co: Cortex; Cpc: Parenchyma cells of cortex; Pi: Pith; Ex: Exodermis; Ep: Epidermis; E: Endodermis; D: Diarch; RC: Root cap; RI: Root primordial cells) 
A comprehensive evaluation of the effects of different treatments on the rooting growth of T. chinensis baokangsis cuttage

The weighted values of the membership functions of cutting rooting indicators and morphological indexes, and the weighted values of each indicator of $T$. chinensis baokangsis cuttings propagation root under different treatments were shown in Table 2 . The weights of 11 cutting indexes were not the same, among which the higher indicator was total root volume (0.154), total length (0.149), total surface area (0.137), adventitious root number (0.129) and rooting index (0.119). The ranking results of the weighted values of the membership functions as following: $\mathrm{A} 1 \mathrm{~B} 1>\mathrm{A} 3 \mathrm{~B} 3>\mathrm{A} 3 \mathrm{~B} 2>\mathrm{A} 2 \mathrm{~B} 1>\mathrm{A} 3 \mathrm{~B} 1>\mathrm{A} 1 \mathrm{~B} 2>\mathrm{A} 1 \mathrm{~B} 3>\mathrm{CK} 1>\mathrm{A} 2 \mathrm{~B} 3>\mathrm{A} 2 \mathrm{~B} 2$. These results indicated that the effect of different growth regulator treatments on the cutting propagation of $T$. chinensis baokangsis was different, and the optimal treatment for rooting growth index was A1B1 (D value 0.792), which is ABT-1+400 mg/L.

Table 2. Membership function evaluation of cuttings root system under different treatments

\begin{tabular}{|c|c|c|c|c|c|c|c|c|c|c|c|c|c|}
\hline \multirow[b]{2}{*}{ Treatment } & \multicolumn{11}{|c|}{ Membership function value: $\mathrm{R}$} & \multirow[b]{2}{*}{ D } & \multirow[b]{2}{*}{ Sequencing } \\
\hline & $\begin{array}{c}\text { Rooting } \\
\text { rate }\end{array}$ & $\begin{array}{c}\text { Callus } \\
\text { rate }\end{array}$ & $\begin{array}{c}\text { Fresh } \\
\text { rate }\end{array}$ & $\begin{array}{l}\text { Indefinite } \\
\text { number }\end{array}$ & $\begin{array}{c}\text { Longest } \\
\text { root length }\end{array}$ & $\begin{array}{c}\text { Rooting } \\
\text { index }\end{array}$ & \begin{tabular}{|l|} 
Total \\
length
\end{tabular} & $\begin{array}{c}\text { Total } \\
\text { projected } \\
\text { area }\end{array}$ & $\begin{array}{l}\text { Total surf- } \\
\text { ace area }\end{array}$ & $\begin{array}{l}\text { Aver-age } \\
\text { diameter }\end{array}$ & $\begin{array}{c}\text { Total- } \\
\text { volume }\end{array}$ & & \\
\hline A1B1 & 1.00 & 0.79 & 0.50 & 0.77 & 1.00 & 0.54 & 1.00 & 0.76 & 0.87 & 0.60 & 0.89 & 0.792 & 1 \\
\hline A1B2 & 0.72 & 1.00 & 0.25 & 0.60 & 0.73 & 0.36 & 0.86 & 0.88 & 0.42 & 0.35 & 0.45 & 0.602 & 6 \\
\hline A1B3 & 0.80 & 0.16 & 1.00 & 0.15 & 0.44 & 0.26 & 0.90 & 0.85 & 0.66 & 0.40 & 0.74 & 0.579 & 7 \\
\hline A2B1 & 0.56 & 0.37 & 0.50 & 0.90 & 0.47 & 0.79 & 0.88 & 1.00 & 1.00 & 0.08 & 0.54 & 0.644 & 4 \\
\hline A2B2 & 0.16 & 0.89 & 0.00 & 0.00 & 0.00 & 0.00 & 0.07 & 0.00 & 0.00 & 0.17 & 0.00 & 0.118 & 10 \\
\hline A2B3 & 0.72 & 0.37 & 0.75 & 0.04 & 0.04 & 0.08 & 1.00 & 0.14 & 0.34 & 0.41 & 0.07 & 0.359 & 9 \\
\hline A3B1 & 0.00 & 0.05 & 0.75 & 1.00 & 0.12 & 0.88 & 0.77 & 0.59 & 0.53 & 1.00 & 1.00 & 0.609 & 5 \\
\hline A3B2 & 1.00 & 0.00 & 0.75 & 0.62 & 0.91 & 0.85 & 0.81 & 0.87 & 0.41 & 0.73 & 0.74 & 0.700 & 3 \\
\hline A3B3 & 0.88 & 0.21 & 1.00 & 0.98 & 0.38 & 1.00 & 0.71 & 0.55 & 0.82 & 0.64 & 0.63 & 0.710 & 2 \\
\hline CK1 & 0.08 & 0.32 & 0.75 & 0.31 & 0.35 & 0.30 & 0.00 & 0.96 & 0.77 & 0.00 & 0.23 & 0.370 & 8 \\
\hline Weight & 0.015 & 0.024 & 0.007 & 0.129 & 0.108 & 0.119 & \begin{tabular}{|l|} 
\\
\end{tabular} & 0.104 & 0.137 & 0.057 & 0.154 & & \\
\hline
\end{tabular}

Effects of different treatments on the soluble substances of cuttings rooting of T. chinensis baokangsis

As shown in Figure 3A, the soluble sugar content in the group of A1B1 treatment was the highest, up to $2.18 \%$, and lowest in the group of $\mathrm{A} 3 \mathrm{~B} 1$ treatment with $1.09 \%$. Except for the treatment of A1B3 and A2B1, the content of the soluble sugar was significantly different between the other groups from the A1B1 group.

As can be seen from Figure 3B, there was no significant difference in soluble protein content among all treatments. The soluble protein content was the highest in the A2B1 group as $14.07 \mathrm{mg}^{-1} \mathrm{~g}^{-1}$, and the lowest was

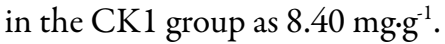

The soluble starch content in the group of $\mathrm{A} 3 \mathrm{~B} 3$ treatment was the highest, up to $1.06 \%$, and the lowest group was $\mathrm{A} 1 \mathrm{~B} 1$ with $0.70 \%$ (Figure $3 \mathrm{C}$ ). In addition, there were a significant differences of soluble starch content between the treatment of CK1 and A3B3, A1B1, A2B2, A2B3.

As shown in Figure 3D, the content of MDA in group of CK1 treatment was the highest with 0.76 umol. $\mathrm{L}^{-1}$, and in the A1B1 treatment was the lowest with $0.46 \mathrm{umol} \cdot \mathrm{L}^{-1}$. The content of MDA in the group of CK1 was significantly different from the treatment of A1B2, A1B1, and A3B2.

\section{Correlation analysis of cutting rooting rate and physiological indexes}

According to the correlation analysis in Table 3, there was a close relationship between the rooting rate and physiological indexes in the cutting rooting process of $T$. chinensis baokangsis. Importantly, the rooting rate was positively correlated with soluble sugar and soluble starch, while extremely significantly negatively correlated with MDA content with a correlation coefficient of -0.493 . 

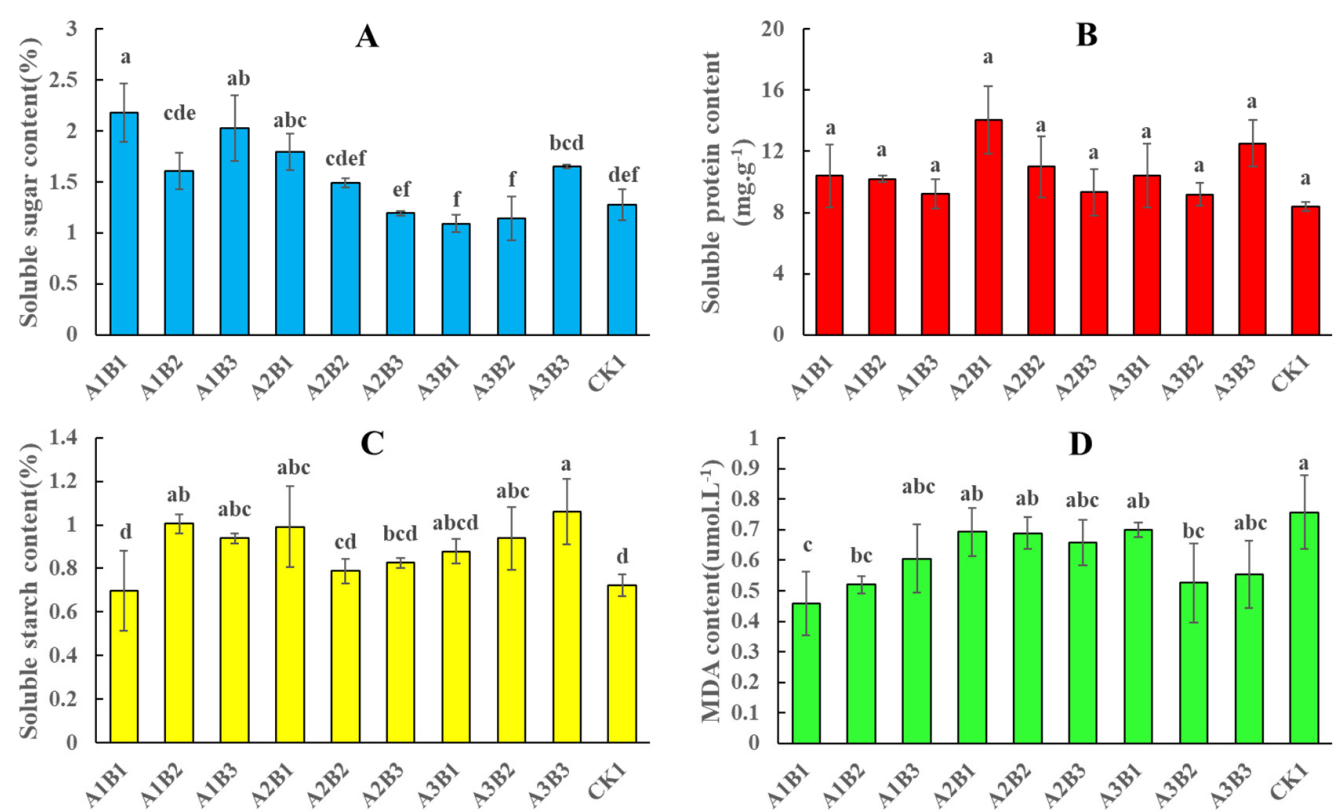

Figure 3. Analysis in physiological indexes of Taxus chinensis (Pilger) Rehd f. baokangsis Y. J. Fei. A, B, C and $\mathrm{D}$ represent the content of soluble sugar, soluble protein, soluble starch and MDA of $T$. chinensis under the treatments with different ABT concentrations, respectively

Each value represents the mean of three replicates of each treatment, and the different normal letters in the same columns indicate significant differences at $\mathrm{P}<0.05$.

Table 3. Correlation analysis between rooting rate and physiological indexes pigment of cuttings

\begin{tabular}{|c|c|c|c|c|c|}
\hline Index & Rooting rate & Soluble sugar & Soluble protein & Soluble starch & MDA \\
\hline Rooting rate & 1 & & & & \\
\hline Soluble sugar & 0.285 & 1 & & & \\
\hline Soluble protein & -0.111 & 0.219 & 1 & & \\
\hline Soluble starch & 0.223 & -0.022 & 0.246 & 1 & \\
\hline MDA & $-0.493^{* *}$ & $-0.416^{*}$ & -0.311 & -0.216 & 1 \\
\hline
\end{tabular}

Effects of different treatments on endogenous hormones of cutting rooting of T. chinensis baokangsis

As shown in Figure 4A, the content of IAA in the most cutting roots after treated with growth regulator was higher than that of the group of CK1, and the IAA content in the roots treated with was highest in the A2B3 treatment, up to $36.15 \mathrm{ng}^{\circ}{ }^{-1}$. Moreover, except treatment of A3B3, the IAA content in all the treatment group were significantly different from those treated with A2B3.

The $\mathrm{ABA}$ content in the control group of $\mathrm{CK} 1$ was significantly higher than that of all groups treated with growth regulator (Figure $4 \mathrm{~B}$ ). In addition, the $\mathrm{ABA}$ content in group of $\mathrm{A} 1 \mathrm{~B} 3$ was not significantly different from A1B1, A1B2, and A3B1, while was significantly different from other treatments.

According to Figure $4 \mathrm{C}$, the $\mathrm{ZR}$ content in most cuttage root after treated with growth regulators was higher than that of the $\mathrm{CK} 1$ group, and in the group of $\mathrm{A} 2 \mathrm{~B} 2$ was the highest, reaching $6.22 \mathrm{ng} \mathrm{g}^{-1}$. Moreover, the significant differences were observed between all groups except for $\mathrm{A} 2 \mathrm{~B} 1$ compared with $\mathrm{A} 2 \mathrm{~B} 3$, and $\mathrm{A} 3 \mathrm{~B} 1$ compared with A3B3.

The $\mathrm{GA}_{3}$ content in cuttage root was significantly higher in the CK1 group compared with in all ABT treatment groups, and except for $\mathrm{A} 3 \mathrm{~B} 2$ and $\mathrm{A} 2 \mathrm{~B} 2$ no statistical significance (Figure 4D). Herein A3B2 and $\mathrm{A} 2 \mathrm{~B} 2$ were significantly different from $\mathrm{A} 2 \mathrm{~B} 1$ and $\mathrm{A} 3 \mathrm{~B} 1$, respectively. 

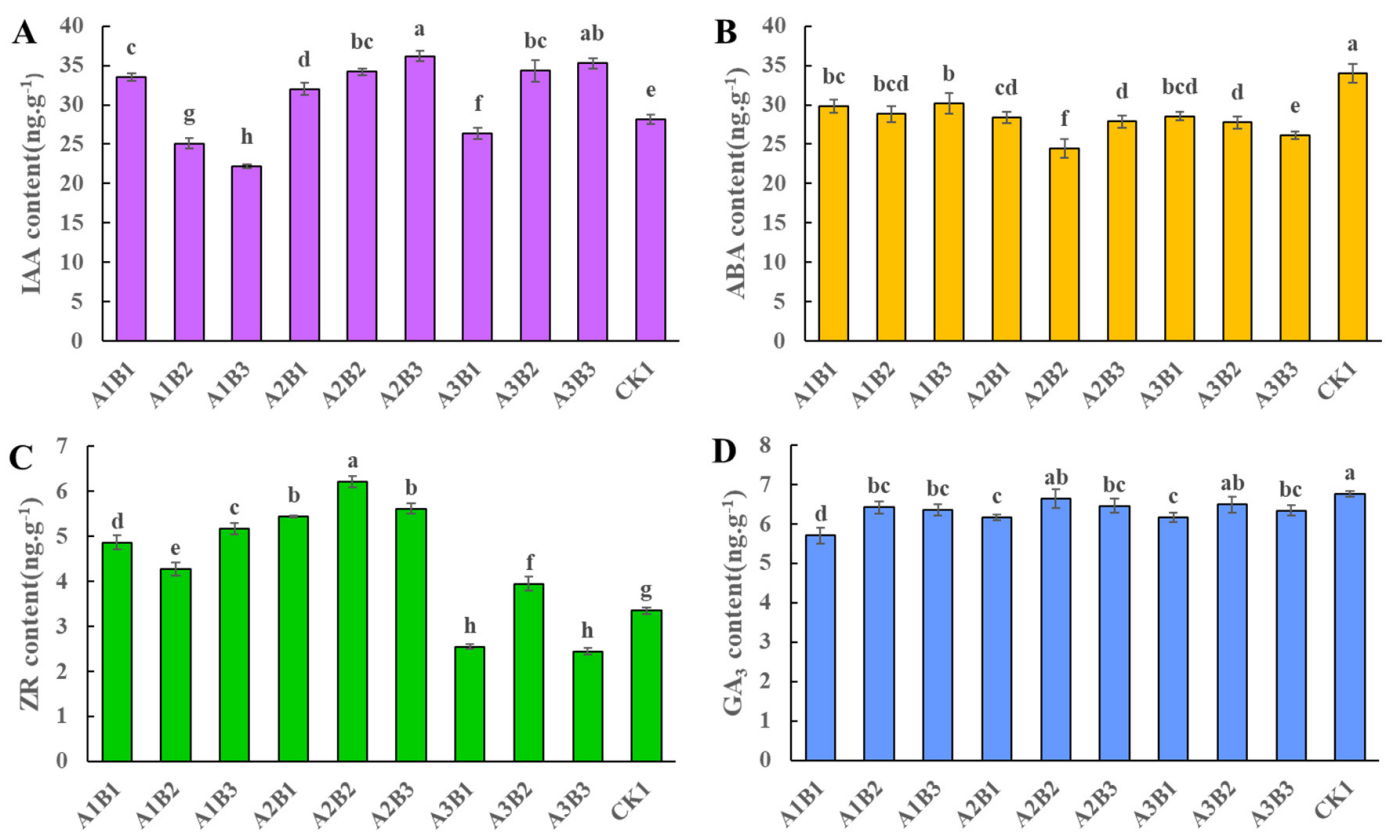

Figure 4. Analysis in endogenous hormones of Taxus chinensis (Pilger) Rehd f. baokangsis Y. J. Fei. A, B, $\mathrm{C}$ and $\mathrm{D}$ represent the content of IAA, $\mathrm{ABA}, \mathrm{ZR}$ and $\mathrm{GA}_{3}$ of $T$. chinensis under the treatments with different ABT concentrations, respectively

Each value represents the mean of three replicates of each treatment, and the different normal letters in the same columns indicate significant differences at $\mathrm{P}<0.05$.

\section{Correlation analysis of cutting rooting rate and endogenous hormones}

From the correlation analysis in Table 4, it can be seen that the rooting rate and endogenous hormones are closely related during the rooting process of $T$. chinensis. The rooting rate was positively correlated with IAA content, negatively correlated with $\mathrm{ABA}, \mathrm{ZR}, \mathrm{GA}_{3}$, and significantly negatively correlated with $\mathrm{GA}_{3}$. The relationship between other enzyme activity indexes is also very close, and the correlation between IAA and $\mathrm{ABA}$ is extremely significantly negatively correlated.

Table 4. Correlation analysis between rooting rate and endogenous hormones of cuttings

\begin{tabular}{|l|c|c|c|c|c|}
\hline \multicolumn{1}{|c|}{ Index } & Rooting rate & IAA & $\mathrm{ABA}$ & $\mathrm{ZR}$ & $\mathrm{GA}_{3}$ \\
\hline Rooting rate & 1 & & & & \\
\hline IAA & 0.173 & 1 & & & \\
\hline $\mathrm{ABA}$ & -0.098 & $-0.492^{* *}$ & 1 & & \\
\hline $\mathrm{ZR}$ & -0.015 & 0.173 & -0.233 & 0.011 & 1 \\
\hline $\mathrm{GA}_{3}$ & $-0.447^{*}$ & -0.042 & 0.032 & & \\
\hline
\end{tabular}

\section{Correlation analysis of rooting rate and endogenous hormones}

According to Table 4, there was a close relationship between rooting rate and endogenous hormones during the cutting rooting of $T$. chinensis baokangsis. Rooting rate was positively correlated with IAA content, negatively correlated with the content of $\mathrm{ABA}$ and $\mathrm{ZR}$, even significantly negatively correlated with $\mathrm{GA}_{3}$. Moreover, the relationship between other indicators was also closely, such as IAA was extremely significantly negatively correlated ABA. 


\section{Discussion}

In this study, we found that the vast majority of $T$. chinensis baokangsis cuttings were first produced callus at the base of the cut, and then differentiated into adventitious roots from the callus. Only a few of adventitious roots were derived from the epidermis, indicating that $T$. chinensis baokangsis belong to the callus rooting type. In terms of time, the cuttings began to form callus after $60 \mathrm{~d}$ and differentiated into adventitious roots at about $150 \mathrm{~d}$. In addition, the cutting freshness rate of all treatment groups was over 93\%, and even reached $100 \%$ in partial treatment groups, and the rooting rate of cuttings was positively correlated with the freshness rate. These results suggested that the cutting effect was better. Our study was consistent with the results of Sun et al. (2020), they proved that ABT treatment can significantly increase the rooting rate of cuttings. In the process of cutting propagation of T. chinensis baokangsis, the optimum adaptive concentration of cuttings to different types of ABT was not the same. OuYang et al. (2015) also found that the optimal concentration of rooting powder for various cutting seedlings was different in the rooting process of Norway spruce, which supported our results. In short, the A1B1 group was the best treatment for the cutting propagation and rooting of $T$. chinensis baokangsis as showed by the results of the membership function.

Root-genesis of cutting propagation is a process that requires to consume a lot of nutrients (Uwe, 2016). The content of soluble sugar and soluble protein in cuttings changes continuously with the development of roots. Soluble sugar is an indispensable nutrient that can be directly absorbed and utilized, and soluble protein is the main existing way of nitrogen in plants, which protect living substances and biofilms in cells, and MDA is the main product of lipid membrane peroxidation, and the formation rate of MDA reflects the level of active oxygen metabolism and the ability of scavenging free radicals in plants (Das and Roychoudhury, 2014; Wang et al., 2015; Su et al., 2017). In this study, the nutrients in cuttings of T. chinensis baokangsis were positively correlated with the rooting rate. In addition, compared with in the CK1 group, the soluble sugar content of most ABT-treated groups was increased, while the soluble protein content was not significantly different, but all were higher than that of the CK1 group. However, the soluble protein content in the A1B1 group with the best comprehensive evaluation was not the highest, indicating that the growth of the root system would lead to the decrease of protein content, which was consistent with the results of El-kenawy (2017) that the soluble protein content was negatively correlated with the number of adventitious roots in cuttings. After treated with ABT, the soluble starch content in each group was higher than that in the CK1 group, while was lower in the A1B1 group. This phenomenon might be explained by the consumption of soluble sugar in the growth of adventitious roots and the degradation of starch into soluble sugar before it could be absorbed and utilized by the cuttings. The content of MDA in the ABT group was lower than that in the control group, and the rooting rate was negatively correlated with MDA content, which was consistent with the conclusion by Liu et al. (2008) that Catalpa bungei cuttings treated with ABT could significantly reduce MDA content, indicating that low MDA content in cuttings contributes to the formation of adventitious roots.

Auxin can significantly promote the growth and development of plant roots (Yang et al., 2019). The application of exogenous IAA to cuttings can regulate the content of endogenous IAA and oxidase activity, thereby achieving the effect of promoting root growth (Wang et al., 2019). By treatment of Canarium album that is a difficult rooting species olive, Wiesman and Lavee (1995) confirmed that the addition of exogenous hormones could significantly improve the rooting ability of cuttings. ABA may inhibit the growth and development of plants (Verslues, 2016). Black (1986) proved that ABA promoted rooting at low concentrations but inhibited rooting at high concentrations in Populus L. In addition, most experiments suggested that $\mathrm{GA}_{3}$ could inhibit rooting, even at a very low concentration (Mauriat et al., 2014). ZR is a kind of cytokinin, which is mainly distributed in the young parts with strong division and can promote cell division and elongation growth. The effect of ZR on root generation has been controversial (Druege et al., 2016). The analysis results of the endogenous hormones of IAA, ABA, ZR and GA3 in the cutting seedlings of T. chinensis baokangsis showed that the rooting rate of cuttings was positively correlated with IAA, negatively correlated with $\mathrm{ABA}$, and $\mathrm{ZR}$, and extremely significantly negative correlated with $\mathrm{GA}_{3}$. These results revealed that the 
occurrence and development of adventitious roots of cutting propagation in T. chinensis baokangsis were closely related to those four endogenous hormones. In addition, we found that compared with the CK1 group, the content of IAA and ZR were increased in most ABT-treated groups, while the content of ABA and $G_{3}$ were decreased. The above results suggested that $A B T$ treatment could up-regulate the content of IAA and ZR and keep them at a certain level, thereby promoting cell division and growth. Meanwhile, ABT treatment could down-regulate the content of $\mathrm{ABA}$, alleviating the hindrance of $\mathrm{ABA}$ on plant growth and development, thus promote the rooting growth of cuttings.

\section{Conclusions}

In conclusions, the T. Chinensis baokangsis belonged to callus rooting type, and the adventitious roots differentiated at about $150 \mathrm{~d}$. For rooting growth indexes, the optimal treatment was ABT-1+400 mg/L. The rooting rate of $\mathrm{T}$. Chinensis baokangsis was positively correlated with the content of soluble sugar, soluble starch, and IAA, while extremely significantly negatively correlated with MDA $(\mathrm{P}<0.01)$. Moreover, the rooting rate also was negatively correlated with $\mathrm{ABA}, \mathrm{ZR}$, and $\mathrm{GA} 3$, and significantly negatively correlated with GA3 $(\mathrm{P}<0.05)$.

\section{Authors' Contributions}

YF conceived and designed the experiments. YM performed the experiments and analyzed the data. YF and $\mathrm{DH}$ contributed reagents/materials/analysis tools. $\mathrm{DH}$ wrote the original draft. $\mathrm{XH}$ wrote review and edited. All authors read and approved the final manuscript.

\section{Acknowledgements}

This work was supported by the National Natural Science Foundation of China (No. 31270740).

\section{Conflict of Interests}

The authors declare that there are no conflicts of interest related to this article.

\section{References}

Babaie H, Zarei H, Nikdel K, Najar FM (2014). Effect of different concentrations of IBA and time of taking cutting on rooting, growth and survival of Ficus binnendijkii'Amstel Queen' cuttings. Notulae Scientia Biologicae 6(2):163166. https://doi.org/10.15835/nsb629281

Black TJ (1986). The physiological role of abscisic acid in the rooting of poplars and aspen stump sprouts. Physiologia Plantarum 67:638-643. https://doi.org/10.1111/j.1399-3054.1986.tb05070.x

Das K, Roychoudhury A (2014). Reactive oxygen species (ROS) and response of antioxidants as ROS-scavengers during environmental stress in plants. Frontiers in Environmental Science 2:53. https://doi.org/10.3389/fenvs.2014.00053

Druege U, Franken P, Hajirezaei MR (2016). Plant hormone homeostasis, signaling, and function during adventitious root formation in cuttings. Frontiers in Plant Science 7:381. https://doi.org/10.3389/fpls.2016.00381

El-kenawy MA (2017). Effect of chitosan, salicylic acid and fulvic acid on vegetative growth, yield and fruit quality of Thompson seedless grapevines. Egyptian Journal of Horticulture 44(1):45-59. https://doi.org/10.21608/EJOH.2017.1104.1007 
Fei YJ, Luo C, Tang W (2019). Differential expression of microRNAs during root formation in Taxus chinensis var. mairei cultivars. Open Life Sciences 14:97-109. https://doi.org/10.1515/biol-2019-0011.

Fei YJ, Tang W (2018). Effects of endogenous indole-3-acetic acid and acetic acid and polyamines on adventitious root formation of Taxus chinensis Lemee et Levl. var. mairei. Propagation of Ornamental Plants 18(2):64-74. http://www.journal-pop.org/2018_18_2_64-74.html

Kose C, Erdal S, Kaya O, Atici O (2011). Comparative evaluation of oxidative enzyme activities during adventitious rooting in the cuttings of grapevine rootstocks. Journal of the science of Food and Agriculture 91(4):738-741. https://doi.org/10.1002/jsfa.4244

Li G, Wan S, Zhou J, Yang Z, Qin P (2010). Leaf chlorophyll fluorescence, hyperspectral reflectance, pigments content, malondialdehyde and proline accumulation responses of castor bean (Ricinus communis L.) seedlings to salt stress levels. Industrial Crops and Products 31(1):13-19. https://doi.org/10.1016/j.indcrop.2009.07.015

Li JH, Zhang XP, Tian SN, Chen YK, Sun QW (2011). Studies on the cutting propagation of Taxus chinensis var. mairei. Journal of Biology 28(6):90-94. https://doi.org/10.1093/mp/ssq070

Liu JL, He W, Su JL (2008). The catalpa bungei Yu Qiu No. 1 cuttage seedling vegetative organ dissection structure with inserts the ear to injury the research which the organization forms. Henan Science 26(7):788-791.

Li SW, Xue LG, Xu SJ, Feng HY, An LZ (2007). Hydrogen peroxide involvement in formation and development of adventitious roots in cucumber. Plant Growth Regulation 52(2):173-180. https://doi.org/10.1007/s10725-0079188-9

Mauriat M, Petterle A, Bellini C, Moritz T (2014). Gibberellins inhibit adventitious rooting in hybrid aspen and Arabidopsis by affecting auxin transport. The Plant Journal 78(3):372-384. https://doi.org/10.1111/tpj.12478

Moustakas M, Sperdouli I, Kouna T, Antonopoulou CI, Therios I (2011). Exogenous proline induces soluble sugar accumulation and alleviates drought stress effects on photosystem II functioning of Arabidopsis thaliana leaves. Plant Growth Regulation 65(2):315-325. https://doi.org/10.1007/s10725-011-9604-Z

Ou Yang FQ, Wang J, Li Y (2015). Effects of cutting size and exogenous hormone treatment on rooting of shoot cuttings in Norway spruce [Picea abies (L.) Karst.]. New Forests 46(1):91-105. https://doi.org/10.1007/s11056-0149449-1

Su DX, Liu H, Zeng QZ, Qi XY, Yao XS, Zhang J (2017). Changes in the phenolic contents and antioxidant activities of citrus peels from different cultivars after invitro digestion. International Journal of Food Science and Technology 52(11):2471-2478. https://doi.org/10.1111/ijfs.13532

Sun J, Xia J, Zhao X, Su L, Li C, Liu P (2020). Effects of 1-aminobenzotriazole on the growth and physiological characteristics of Tamarix chinensis cuttings under salt stress. Journal of Forestry Research 1-11. https://doi.org/10.1007/s11676-020-01215-6

Tan G F (2014). The experiment of Tamarix chinensis Lour. tender branch cuttage. Journal of Jilin Forestry Science and Technology 43(6):11-13. https://doi.org/10.16115/j.cnki.issn.1005-7129.2014.06.027

Uwe D, Philipp F, Hajirezaei MR (2016). Plant hormone homeostasis, signaling and function during adventitious root formation in cuttings. Frontiers in Plant Science 31(7):381-395. https://doi.org/10.3389/fpls.2016.00381

Verslues, PE (2016). ABA and cytokinins: challenge and opportunity for plant stress research. Plant Molecular Biology 91(6):629-640. https://doi.org/10.1007/s11103-016-0458-7

Wang Y, Li J, Dong LH, Wu QH, Li L, Yang HL, Zhang MW, Su DX (2019). Effects of thermal processing methods and simulated digestion on the phenolic content and antioxidant activity of lotus leaves. Journal of Food Processing and Preservation 43(2):e13869. https://doi.org/10.1111/jfpp.13869

Wiesman Z, Lavee S (1995). Enhancement of IBA stimulatory effect on rooting of olive cultivar stem cuttings. Scientia Horticulture 65:189-198. https://doi.org/10.1016/0304-4238(95)00772-L

Yang JM, Ye T, Liu GH, Xu XT, Zheng YX, Wang WK (2019). Synthesis and bioactivity of indoleacetic acidcarbendazim and its effects on Cylindrocladium parasiticum. Pesticide Biochemistry and Physiology 158:128-134. https://doi.org/10.1016/j.pestbp.2019.05.001

Zhang WX, Fan JX, Tan QX, Zhao MM, Zhou T, Cao FL (2017). The effects of exogenous hormones on rooting process and the activities of key enzymes of Malus hupehensis stem cuttings. PLoS One 12(2):e0172320. https://doi.org/10.1371/journal.pone.0172320 
OPEN ACCESS

(c) (2)

The journal offers free, immediate, and unrestricted access to peer-reviewed research and scholarly work. Users are allowed to read, download, copy, distribute, print, search, or link to the full texts of the articles, or use them for any other lawful purpose, without asking prior permission from the publisher or the author.

License - Articles published in Notulae Botanicae Horti Agrobotanici Cluj-Napoca are Open-Access, distributed under the terms and conditions of the Creative Commons Attribution (CC BY 4.0) License. (C) Articles by the authors; UASVM, Cluj-Napoca, Romania. The journal allows the author(s) to hold the copyright/to retain publishing rights without restriction. 